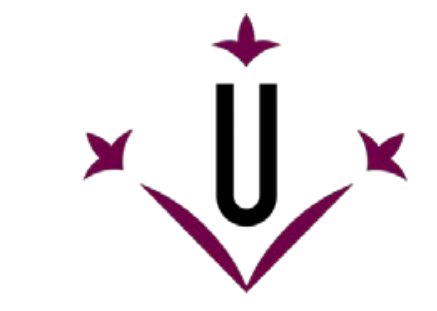

Universitat de Lleida

Document downloaded from:

http://hdl.handle.net/10459.1/63263

The final publication is available at:

https://doi.org/10.2527/jas.2014-8029

Copyright

(c) American Society of Animal Science, 2014 


\title{
Associations between pig adiponectin (ADIPOQ) genotype and serum lipid levels are modulated by age-specific modifiers ${ }^{1}$
}

\author{
A. Castelló,* * R. Quintanilla, $\uparrow$ C. Melo,* D. Gallardo, \\ A. Manunza,* J. L. Noguera, $\uparrow$ J. Tibau, $\uparrow$ J. Jordana, + R. N. Pena,, and M. Amills* ${ }^{2}$ \\ *Department of Animal Genetics, Center for Research in Agricultural Genomics (CSIC-IRTA-UAB-UB), Campus de la Universitat \\ Autònoma de Barcelona, Bellaterra, 08193 Spain; \$Departament de Ciència Animal i dels Aliments, Facultat de Veterinària, \\ Universitat Autònoma de Barcelona, Bellaterra, 08193 Spain; †IRTA, Genètica i Millora Animal, Torre Marimon, 08140 Caldes de \\ Montbui, Spain; and §Department of Animal Production, University of Lleida-Agrotecnio Center, 25198, Lleida, Spain
}

\begin{abstract}
The adiponectin $(A D I P O Q)$ locus is a positional and functional candidate gene for 2 porcine chromosome 13 (SSC13) QTL influencing cholesterol (CHOL) and low-density lipoprotein (LDL) concentrations in 190-d-old pigs. By sequencing $2.37 \mathrm{~kb}$ of the pig $A D I P O Q$ cDNA, we have identified $1 \mathrm{c} . * 1512 \mathrm{G}>$ $\mathrm{T} 3^{\prime}$ untranslated region polymorphism that has been genotyped in a Duroc pig commercial population with records for serum lipid levels at 45 and $190 \mathrm{~d}$ of age. Statistical analysis of the data have revealed significant associations between the $A D I P O Q$ genotype and CHOL $(P=0.0040)$ and $\operatorname{LDL}(P=0.0011)$ concentrations at $190 \mathrm{~d}$ but not at $45 \mathrm{~d}$. In family 3, most of the SSC13 QTL effects on LDL levels at $190 \mathrm{~d}$ were explained
\end{abstract}

by the $A D I P O Q$ genotype. We also found an association with triglyceride levels at $45 \mathrm{~d}(P=0.0060)$ but not at $190 \mathrm{~d}$. Measurement of allelic mRNA imbalance demonstrated that the $\mathrm{G}$ and $\mathrm{T}$ alleles are expressed at very similar levels in muscle and fat tissues, indicating that the c.*1512G $>$ T polymorphism does not affect transcript abundance. As a whole, results obtained in the current work as well as previous data gathered in humans and pigs provide evidence that the magnitude of associations between blood lipid phenotypes and candidate loci genotypes may vary depending on the age of the individual, therefore suggesting the existence of dynamic genotype $\times$ environment interactions changing on a temporal scale.

Key words: adiponectin, cholesterol, low-density lipoprotein, pig, pyrosequencing, triglyceride

(C) 2014 American Society of Animal Science. All rights reserved.

J. Anim. Sci. 2014.92:5367-5373

doi:10.2527/jas2014-8029

\section{INTRODUCTION}

Lipid concentrations are one of the major risk factors determining the susceptibility to coronary diseases, with reduced high-density lipoprotein (HDL) to low-density lipoprotein (LDL) concentration ratio being considered an important predisponent factor.

\footnotetext{
${ }^{1}$ This work has been funded by grants AGL2007-66707-C02, AGL201022208-C02-01, and AGL2010-22208-C02-02 (Ministerio de Ciencia e Innovación) and CSD 2007-00036 (Ministerio de Ciencia e Innovación, Consolider Ingenio 2010 Program). The authors are indebted to Selección Batalle S.A. for providing the animal material and for their cooperation in the experimental protocol. D. Gallardo and C. Melo were funded with fellowships from the Universitat Autònoma de Barcelona and the Instituto Agronómico Mediterráneo, respectively. A. Zidi received a contractual grant under the framework of CSD 2007-00036.

2Corresponding author: Marcel.Amills@uab.cat

Received May 6, 2014.

Accepted September 23, 2014.
}

The close physiological similarities between pigs and humans have prompted the use of the former as a suitable biomedical model to investigate the genetic factors that modulate serum lipid levels (Casellas et al., 2013). Gallardo et al. (2008) explored the genomic architecture of serum lipid concentrations at 45 and 190 $\mathrm{d}$ by performing a genome scan in a Duroc commercial population. In doing so, they identified a chromosome 13 (SSC13) genomic region containing 2 chromosomewide significant QTL for cholesterol (CHOL) and LDL concentration at $190 \mathrm{~d}$ (CHOL190 and LDL190, respectively). Genotyping of additional microsatellites allowed the fine mapping of these QTL to the $60 \mathrm{Mb}$ interval defined by markers S0068 and SW398 (unpublished data). The analysis of the gene content of this region resulted in the identification of the adiponectin $(A D I P O Q)$ locus as a candidate gene to explain the segregation of the CHOL190 and LDL190 QTL. 
Adiponectin, the most abundant secretory product of white fat tissue, is an adipokine with multiple effects on carbohydrate and lipid metabolism (Chandran et al., 2003). In this way, ADIPOQ upregulates insulin signaling (stimulating glucose utilization), decreases tissue triglyceride (TRIG) content, promotes fatty acid oxidation, and inhibits the formation of atherosclerotic plaques (Chandran et al., 2003; Kadowaki and Yamauchi, 2005). In pigs, the $A D I P O Q$ genotype has been associated with loin muscle width and depth and loin eye area (Cieslak et al., 2013) as well as with ADG, weight of neck and loin, and feed:gain ratio (Dall'Olio et al., 2009). The goal of the current work was to characterize the variability of the pig ADIPOQ gene and investigate its association with serum lipid concentrations in a Duroc commercial population.

\section{MATERIALS AND METHODS}

\section{Animal Material and Phenotype Recording}

All experimental procedures, traits recording, and blood sampling were approved by the Ethical Committee of the Institut de Recerca i Tecnologia Agroalimentàries (IRTA). Our original experimental design involved the mating of 5 boars with approximately 400 sows and selecting 1 male offspring per litter at random. However, this was not possible in some instances (i.e., litters without weaned male piglets) and diseases and other problems caused losses during the fattening period. In consequence, the final dataset comprised 350 barrows distributed in 5 half-sib families (Lipgen population), born in 3 farms and divided in 4 batches (Gallardo et al., 2008). After weaning, barrows were transferred to the experimental test station at the Centre de Control Porcí of the IRTA. Cholesterol, TRIG, LDL, and HDL concentrations were measured at 45 (CHOL45, LDL45, HDL45, and TRIG45) and $190 \mathrm{~d}$ (CHOL190, LDL190, HDL190, and TRIG190) following the methods reported by Gallardo et al. (2008). We chose these 2 time points because they are representative of 2 distinct physiological states, that is, piglets at weaning and adult pigs. To ensure normality, data were logtransformed before carrying out association analyses.

\section{Sequencing of the Porcine ADIPOQ Gene}

To characterize the variability of the porcine $A D I P O Q$ gene, we purified total RNA from 9 pig skeletal muscle samples, following protocols described by Gallardo et al. (2009). These samples came from individuals with distinct genotypes for the SSC13 LDL QTL (i.e., QQ vs. qq). Complementary DNA was synthesized by reverse transcription (RT) with the ThermoScript RTPCR system kit (Invitrogen, Life Technologies, Madrid,
Table 1. Whole-population association analysis between log-transformed serum lipid concentrations ${ }^{1}$ at 45 and $190 \mathrm{~d}$ of age and pig $A D I P O Q$ genotypes

\begin{tabular}{lcccc}
\hline \hline & & \multicolumn{3}{c}{ Least squares means ${ }^{3}$ of $A D I P O Q$ genotypes } \\
\cline { 3 - 5 } Phenotype $^{1}$ & $P$-value & TT & GT & GG \\
\hline CHOL45 & $0.4438 \mathrm{~ns}$ & $1.902(79.9)$ & $1.882(76.3)$ & $1.882(76.2)$ \\
HDL45 & $0.4800 \mathrm{~ns}$ & $1.496(31.4)$ & $1.474(29.8)$ & $1.475(29.9)$ \\
LDL45 & $0.9162 \mathrm{~ns}$ & $1.568(37.0)$ & $1.566(36.9)$ & $1.572(37.4)$ \\
TRIG45 & $0.0060^{4}$ & $1.666^{\mathrm{a}}(46.3)$ & $1.617^{\mathrm{a}}(41.4)$ & $1.582^{\mathrm{b}}(38.2)$ \\
CHOL190 & $0.0040^{4}$ & $2.101^{\mathrm{a}}(126.1)$ & $2.072^{\mathrm{b}}(118.1)$ & $2.102^{\mathrm{a}}(126.6)$ \\
HDL190 & $0.2107 \mathrm{~ns}$ & $1.727(53.4)$ & $1.699(50.0)$ & $1.707(50.9)$ \\
LDL190 & $0.0011^{4}$ & $1.790^{\mathrm{ab}}(61.7)$ & $1.753^{\mathrm{b}}(56.6)$ & $1.805^{\mathrm{a}}(63.9)$ \\
TRIG190 & $0.5743 \mathrm{~ns}$ & $1.665(46.3)$ & $1.651(44.8)$ & $1.675(47.3)$ \\
\hline
\end{tabular}

${ }^{\mathrm{a}, \mathrm{b}}$ Within rows, least squares means displaying significant differences are indicated with different superscript letters.

${ }^{1} \mathrm{CHOL} 45=$ cholesterol concentration at $45 \mathrm{~d}$; HDL45 = high-density lipoprotein concentration at $45 \mathrm{~d}$; LDL45 $=$ low-density lipoprotein concentration at $45 \mathrm{~d}$; TRIG45 = triglyceride concentration at $45 \mathrm{~d}$; CHOL190 $=$ cholesterol concentration at $190 \mathrm{~d}$; HDL190 = high-density lipoprotein concentration at $190 \mathrm{~d} ;$ LDL190 = low-density lipoprotein concentration at $190 \mathrm{~d}$; TRIG190 = triglyceride concentration at $190 \mathrm{~d}$.

${ }^{2}$ Statistical significances, expressed as $P$-values, of the $A D I P O Q$ genotype effect in the general linear model analysis of the whole population data. ns $=$ nonsignificant.

${ }^{3}$ Serum lipid concentrations are expressed in log-milligram/deciliter units, while raw values $(\mathrm{mg} / \mathrm{dL})$ are shown between parentheses.

${ }^{4}$ Significant differences after correction for multiple testing.

Spain) following the protocols described by Melo et al. (2013). The amplification of most of the coding region and $3^{\prime}$ untranslated region (UTR) of the pig $A D I P O Q$ cDNA involved several PCR reactions (Supplementary Table 1). Their composition was $2 \mathrm{mM} \mathrm{MgCl} 2,200 \mu M$ deoxyribonucleotide triphosphates (dNTP), $0.5 \mu M$ of each primer, 1.25 units BIOTAQ DNA polymerase (Bioline, London, UK), and $2 \mu \mathrm{L}$ RT reaction in a final volume of $25 \mu \mathrm{L}$. The PCR thermal profile was 30 cycles of $94^{\circ} \mathrm{C}$ for $1 \mathrm{~min}$, annealing temperature (Supplementary Table 1) for $1 \mathrm{~min}$, and $72^{\circ} \mathrm{C}$ for $2 \mathrm{~min}$. Amplicons were purified with the USB ExoSAP-IT PCR Product Cleanup protocol (Isogen, Badalona, Spain) and directly sequenced using the BigDye Terminator Cycle Sequencing v3.1 kit (Applied Biosystems, Life Technologies, Madrid, Spain) and primers described in Supplementary Table 1.

\section{Genotyping of the ADIPOQ Locus}

A pyrosequencing protocol (Ronaghi et al., 1998) was developed to genotype a c.*1512G > T ADIPOQ SNP in the Lipgen population. A 177 bp 3' UTR fragment containing this SNP was amplified with primers detailed in Supplementary Table 2. The following thermal profile was used: $95^{\circ} \mathrm{C}$ for $10 \mathrm{~min}, 40$ cycles at $95^{\circ} \mathrm{C}$ for $1 \mathrm{~min}$, $62^{\circ} \mathrm{C}$ for $1 \mathrm{~min}$ and $72^{\circ} \mathrm{C}$ for $1 \mathrm{~min}$, and a final extension step of $7 \mathrm{~min}$ at $72^{\circ} \mathrm{C}$. Composition of this reaction was 
Table 2. Least-squares means of the $A D I P O Q$ genotype effect on the log-transformed serum lipid concentrations at 45 or 190 d nested within family

\begin{tabular}{|c|c|c|c|c|c|c|c|c|c|}
\hline \multirow[b]{3}{*}{ Family } & \multicolumn{9}{|c|}{ Least squares means ${ }^{1}$ of ADIPOQ genotypes } \\
\hline & \multicolumn{3}{|c|}{ TRIG45 $(P=0.0305)^{2}$} & \multicolumn{3}{|c|}{ CHOL190 $(P=0.0387)^{2}$} & \multicolumn{3}{|c|}{ LDL190 $(P=0.0206)^{2}$} \\
\hline & TT & GT & GG & TT & GT & GG & TT & GT & GG \\
\hline 1 & 1.683 & 1.659 & 1.594 & 2.131 & 2.085 & 2.084 & 1.820 & 1.787 & 1.767 \\
\hline 2 & $1.778^{\mathrm{a}}$ & $1.651^{\mathrm{b}}$ & $1.600^{\mathrm{b}}$ & 2.110 & 2.093 & 2.094 & 1.790 & 1.776 & 1.780 \\
\hline 3 & 1.549 & 1.582 & 1.558 & $2.095^{\mathrm{ab}}$ & $2.056^{\mathrm{a}}$ & $2.131^{\mathrm{b}}$ & $1.786^{\mathrm{ab}}$ & $1.733^{\mathrm{a}}$ & $1.852^{\mathrm{b}}$ \\
\hline 4 & 1.622 & 1.595 & 1.550 & 2.075 & 2.060 & 2.068 & 1.766 & 1.729 & 1.767 \\
\hline
\end{tabular}

$2.5 \mathrm{~m} M \mathrm{MgCl}_{2}, 250 \mu M \mathrm{dNTP}, 0.3 \mu M$ of each primer, 1.25 units of AmpliTaq Gold DNA polymerase (Applied Biosystems), and $60 \mathrm{ng}$ of genomic DNA in a final volume of $25 \mu \mathrm{L}$. The biotinylated PCR product was prepared for pyrosequencing analysis according to the manufacturer's instructions (Pyrosequencing, Qiagen, Madrid, Spain). Pyrosequencing reactions included $20 \mu \mathrm{L}$ of PCR, the sequencing primer at $0.3 \mu M$, and PyroMark Gold Q96 reagents (Pyrosequencing, Qiagen), being run in a PSQ HS96 system and analyzed with the PSQ HS96A 1.2 software (Pyrosequencing, Qiagen). A total of 311 barrows were successfully genotyped.

\section{Performance of Association Analysis with Phenotypes of Economic and Biomedical Interest}

Association studies between the $A D I P O Q$ genotype and serum lipid measurements at 45 and $190 \mathrm{~d}$ of age were performed by means of the GLM procedure of SAS (SAS Inst. Inc., Cary, NC). Models used for this analysis (whole-population analysis 1) were

$$
\begin{aligned}
y_{i j k l}= & \mu+b_{i}+l_{j}+\beta \operatorname{cov}_{i j k}+\operatorname{gen}_{k}+e_{i j k}, \\
& \text { for records at } 45 \mathrm{~d}, \\
y_{i j k l}= & \mu+\mathrm{b}_{\mathrm{i}}+\mathrm{d}_{\mathrm{j}(\mathrm{i})}+\beta \operatorname{cov}_{\mathrm{ijk}}+\operatorname{gen}_{\mathrm{k}}+\mathrm{e}_{\mathrm{ijk}}, \\
& \text { for records at } 190 \mathrm{~d}(\operatorname{model}[\mathrm{G}]),
\end{aligned}
$$

and

in which $y_{i j k}$ represents the log-transformed phenotypic observation of individual $k$ in the $i$ th and $j$ th levels of the corresponding systematic effects; $b_{i}$ is the systematic effect of the $i$ th batch of fattening (4 levels); $f_{j}$ is the systematic effect of $j$ th farm of origin (3 levels, significant only for records at $45 \mathrm{~d}) ; d_{j(i)}$ is the fixed effect of the $j$ th date of blood extraction, nested within the $i$ th fattening batch ( 2 dates of extraction at $190 \mathrm{~d}$ per batch); $\beta$ and $\operatorname{cov}_{i j k}$ are, respectively, the regression coefficient and the covariate (backfat thickness); gen $_{k}$ is the effect of the $k$ th genotype for the analyzed polymorphism at the $A D I P O Q$ gene (3 levels: TT, GT, and GG); and $e_{i j k}$ is the residual effect. To test the consistence across families of the associations found in analysis 1 , we also performed a within-family association analysis (analysis 2) considering the $A D I P O Q$ genotype effect $\left(\right.$ gen $\left._{k}\right)$ nested within each paternal family (families 1 to 5). Significance of the $A D I P O Q$ genotype was set on the basis of $F$-statistics comparing models reported above with a model without gene effects. In all analyzed traits, least squares means for the 3 genotypes were computed and subsequently compared with a $t$ test of significance.

The $A D I P O Q$ gene maps to a $\mathrm{SSC} 13$ region (Dai et al., 2006) that contains QTL for CHOL190 and LDL190 (Gallardo et al., 2008). Given that 1) CHOL is fundamentally composed of HDL and LDL and 2) we did not detect any QTL for HDL in the Lipgen population, we have considered that in family 3 the CHOL SSC13 QTL might be mostly explained by the existence of the LDL QTL. Taking this into account, and to exclude that the associations found in analysis 2 are produced by the SSC13 LDL190 QTL and not by the ADIPOQ genotype, we made a third analysis of the family 3 dataset (analysis 3 ) with the following models:

$$
\begin{aligned}
& \begin{aligned}
y_{i j k l}= & \mu+b_{i}+\mathrm{d}_{\mathrm{j}(\mathrm{i})}+\beta \operatorname{cov}_{\mathrm{ijkl}}+\alpha \mathrm{p}_{\mathrm{ijkl}}+\mathrm{e}_{\mathrm{ijk}}, \\
& \operatorname{model}[\mathrm{Q}],
\end{aligned} \\
& \begin{aligned}
y_{i j k l}= & \mu+b_{i}+\mathrm{d}_{\mathrm{j}(\mathrm{i})}+\beta \operatorname{cov}_{\mathrm{ijkl}}+\operatorname{gen}_{\mathrm{k}}+\alpha \mathrm{p}_{\mathrm{ijkl}}+\mathrm{e}_{\mathrm{ijkl}}, \\
& \operatorname{model}[\mathrm{GQ}],
\end{aligned}
\end{aligned}
$$
and

in which $p_{i j k l}$ is the probability of individual $l$ inheriting a given allele from its common parent at the QTL peak (72 cM at SSC13) as reported by Gallardo et al. (2008) and $\alpha$ is the regression coefficient of phenotypes onto the probability of having inherited a given allele from the common parent, that is, the QTL allele substitution effect in paternal family 3 . Two additional $F$-statistics 
were computed to compare model [GQ] (includes both the QTL and $A D I P O Q$ effects) with model [G] (considers only the $A D I P O Q$ effect, see analysis 1) or model [Q] (takes into account only the QTL effect).

\section{Analysis of Allelic mRNA Expression Imbalance in Tissue Samples}

Total RNA was purified from backfat adipose tissue and gluteus medius and longissimus dorsi skeletal muscle samples obtained from 16 heterozygous GT individuals, as previously described (Gallardo et al., 2009). Complementary DNA was synthesized from $1 \mu \mathrm{g}$ total RNA, treated with TURBO DNA-free kit (Ambion, Life Technologies, Madrid, Spain), by using the High Capacity cDNA Transcription Kit (Applied Biosystems). The final volume of the reaction was $20 \mu \mathrm{L}$. One microliter of the synthesized cDNA was used as a PCR template (same primers and conditions used in the genotyping protocol). Preparation of amplicons and pyrosequencing reactions were performed as described in the previous section. Pyrosequencing data were quantified and background was corrected by using the AQ mode of SNP analysis implemented in the PSQ HS96A 1.2. software (Pyrosequencing, Qiagen). We checked that this assay estimates allele-specific frequencies in a precise manner by analyzing mixtures of genomic DNA of GG and TT homozygous pigs at different proportions (Supplementary Fig. 1). Following Bischoff et al. (2009), we used a 2-tailed $t$ test with unequal variances to infer if there is allelic imbalance. More specifically, we compared the distributions of the ratios of the $G$ vs. T alleles in pyrograms obtained from genomic DNA samples (where ratios between both alleles should be equal to the unity) and in pyrograms obtained from cDNA samples (where ratios can be different from 1 if there is allelic imbalance).

\section{RESULTS AND DISCUSSION}

In a previous study (unpublished data), we identified 1 SSC13 LDL QTL in the $60 \mathrm{Mb}$ interval defined by markers S0068 and SW398. By screening this region with the BioMart tool (www.ensembl.org/biomart/), we identified several candidate genes related to lipid metabolism (Supplementary Table 3). Moreover, we performed a complementary screening of the orthologous human genomic region that enabled us to identify the $A D I P O Q$ gene. This locus cannot be found in the current Ensembl (Sscrofa10.2; www.ensembl.org) porcine genome release, but Dai et al. (2006) mapped it to the SSC13q36-41 interval. Among the candidate genes mentioned above, we selected $A D I P O Q$ for 2 main reasons. First, this adipokine has a fundamental role in TRIG and LDL me-
Table 3. Ratios of the relative frequencies of the $\mathrm{G}$ and $\mathrm{T}$ alleles in cDNA and genomic DNA (gDNA) samples obtained from heterozygous GT pigs

\begin{tabular}{lccc}
\hline \hline Tissue & $\mathrm{G} / \mathrm{T}_{\text {cDNA ratio }}{ }^{1}$ & $\mathrm{G} /$ T $_{\text {gDNA ratio }}{ }^{2}$ & $P$-value \\
\hline Gluteus medius muscle & $1.160 \pm 0.045$ & $1.106 \pm 0.016$ & 0.278 \\
Longissimus dorsi muscle & $1.142 \pm 0.050$ & $1.097 \pm 0.016$ & 0.394 \\
Backfat & $1.153 \pm 0.054$ & $1.094 \pm 0.015$ & 0.311 \\
\hline
\end{tabular}

${ }^{1}$ Mean $\pm \mathrm{SE}$ of the ratio between $\mathrm{G}$ and $\mathrm{T}$ relative allelic frequencies estimated from cDNA samples.

${ }^{2}$ Mean $\pm \mathrm{SE}$ of the ratio between $\mathrm{G}$ and $\mathrm{T}$ relative allelic frequencies estimated from genomic DNA samples.

tabolism in humans (Qiao et al., 2008; Lara-Castro et al., 2006). Second, in a previous study where we compared gene expression in Duroc pigs with high vs. low fatness profiles coming from the same Lipgen population examined herewith, we observed that the $A D I P O Q$ gene was upregulated in the fattest pigs (Cánovas et al., 2010).

Sequencing of approximately $99 \%$ of the $A D I P O Q$ coding region in 9 individuals (GenBank accession number JX092267) with alternate genotypes (QQ vs. qq) for the SSC13 QTL enabled us to detect $1 \mathrm{c} .{ }^{*} 1512 \mathrm{G}>\mathrm{T}$ SNP at the 3' UTR (Single Nucleotide Polymorphism Database, www.ncbi.nlm.nih.gov/SNP/, submitted SNP number 1067316817). This SNP was genotyped (Supplementary Fig. 2) in the Lipgen population by using a pyrosequencing protocol (Ronaghi et al., 1998). Genotype frequencies of the c. ${ }^{*} 1512 \mathrm{G}>\mathrm{T}$ SNP in the Lipgen population were GG, 0.386; GT, 0.489; and TT, 0.125 (see Supplementary Table 4 for the distribution of genotype frequencies among families). Houde et al. (2008) reported the existence of 4 SNP (1 in the coding region and 3 in the $3^{\prime}$ UTR), but 3 of them had minimum allelic frequencies of 0.05 . Similarly, Dall'Olio et al. (2009) described 1 exonic SNP with a MAF of 0.12 in Italian Duroc pigs. On the basis of these results and ours, we may infer that the $A D I P O Q$ gene displays a moderate level of variability in Duroc pigs.

After correction for multiple testing, significant associations were found between the $A D I P O Q$ genotype and TRIG45 $(P=0.0060)$, in spite of the fact that Gallardo et al. (2008) did not find any QTL for this trait on SSC13 (Table 1). This finding agrees well with the fact that adiponectin concentration is considered to be a marker of TRIG-rich lipoprotein metabolism (Chan et al., 2005; Qiao et al., 2008). Indeed, Qiao et al. (2008) produced mice with a 12-fold increased expression of ADIPOQ by using an adenoviral vector and observed a $40 \%$ reduction of plasma TRIG and free fatty acid levels. More importantly, these authors found a $40 \%$ increase in muscle lipoprotein lipase (LPL) activity as well as a significant increase in muscle very low density lipoprotein receptor and LPL expression.

We also found significant associations between the ADIPOQ genotype and CHOL190 $(P=0.0040)$ and 
LDL190 $(P=0.0011)$. In the case of CHOL190, heterozygous individuals displayed lower means than the 2 homozygous genotypes. This pattern of underdominance is difficult to explain from a functional perspective because the molecular basis of dominance is not yet fully understood, but similar results have been obtained in mouse, where underdominant QTL for serum lipids (Lawson et al., 2010) and carotid atherosclerosis (Rowlan et al., 2013) have been reported so far.

Previous data obtained in humans provided evidence that adiponectin levels are negatively correlated with LDL concentrations (Kantartzis et al., 2006) and LDL particle size (Lara-Castro et al., 2006). To evaluate the consistence across families of the associations presented at Table 1, we performed a within-family association analysis (Table 2). This approach allowed us to infer that associations with TRIG45 (family 2) as well as with CHOL190 and LDL190 (families 3 and 5) are family specific (Table 2). As shown in Supplementary Table 5, the magnitudes and directions of allele substitution effects varied across families, and they reached significance only in families 3 and 5. This finding points to the c. ${ }^{* 1512 G}>\mathrm{T}$ SNP as a marker linked to an unidentified causal mutation rather than having causal effects by itself (if so, we would expect to see consistent effects across families). It is also worth mentioning that we did not find any association between the ADIPOQ genotype and serum CHOL45, LDL45, or TRIG190 concentrations. Indeed, Gallardo et al. (2008) observed a complete lack of positional concordance between QTL for serum lipid traits measured at 45 and $190 \mathrm{~d}$ (Gallardo et al., 2008). These findings suggest that associations between the $A D I P O Q$ genotype and lipid phenotypes are modulated by age-specific factors.

We were interested in investigating if the $A D I P O Q$ genotype explains, totally or in part, the segregation of a SSC13 LDL190 QTL detected in family 3 by Gallardo et al. (2008), so we performed a more refined analysis where the effects of these 2 factors can be disentangled. When we compared the model with the QTL and the $A D I P O Q$ genotype (model [GQ]) with the model with the QTL (model [Q]), the contrast happened to be significant $\left(F_{3 \mathrm{df}}=3.28, P=0.0260\right)$. Conversely, the comparison of the model [GQ] with the model with the $A D I P O Q$ genotype (model $[\mathrm{G}]$ ) was nonsignificant $\left(F_{2 \mathrm{df}}\right.$ $=2.65, P=0.1081)$. These results provide evidence that a relevant fraction of the $\mathrm{SSC} 13$ genetic variation associated with LDL190 concentrations in family 3 resides within or near the $A D I P O Q$ gene.

Although the within-family analysis 2 did not provide evidence of a causal effect for the c. ${ }^{*} 1512 \mathrm{G}>\mathrm{T}$ SNP, we aimed to obtain a complementary view into this issue by combining in silico and functional approaches. In principle, polymorphisms at the 3' UTR may display functional effects by decreasing mRNA stability and translatability (Wang et al., 2006). Indeed, the rs6773957 SNP located in the $3^{\prime}$ UTR of the human $A D I P O Q$ gene has been associated with adiponectin levels (Hivert et al., 2008). We used the UTRscan (Pesole and Liuni, 1999) and the Patrocles software (Hiard et al., 2010) to investigate if the c. ${ }^{*} 1512 \mathrm{G}>\mathrm{T}$ SNP creates or disrupts a functional motif or a microRNA site at the $3^{\prime}$ UTR, but we did not obtain any conclusive results. We performed an additional analysis with UNAFold (Markham and Zuker, 2008) to find out if the 3' UTR SNP causes a change in the secondary structure of the mRNA. The UNAFold prediction (Supplementary Fig. 3) showed a slight difference in the free energies of both alleles (G $<\mathrm{T}$, so the $\mathrm{G}$ allele conformation would be more stable) and a subtle conformational change.

We decided to investigate the differential expression of both alleles by using a quantitative pyrosequencing assay. Once wevalidated the accuracy of this approach (Supplementary Fig. 1), it was applied to estimate allele-specific frequencies of RT ADIPOQ PCR products in backfat adipose tissue and gluteus medius and longissimus dorsi skeletal muscle samples obtained from 16 heterozygous GT individuals. This quantitative analysis clearly showed that the $\mathrm{G}$ and $\mathrm{T}$ alleles are expressed at similar levels in the 3 analyzed body sites (Table 3 ). These findings indicate that the c.* ${ }^{*} 1512 \mathrm{G}>\mathrm{T}$ SNP is not associated with transcript abundance, at least in the 2 tissues under analysis. Although we cannot completely rule out a causal effect through posttranscriptional mechanisms (e.g., by altering the binding of a microRNA and protein translation), the absence of a relationship between the $A D I P O Q$ genotype and mRNA levels plus the family-specific pattern of the associations found (Table 2) strongly suggest a scenario of linkage between the c. ${ }^{*} 1512 \mathrm{G}>\mathrm{T}$ SNP and 1 or several causal mutations yet to be found.

In summary, we have shown that the $A D I P O Q$ genotype is associated with serum CHOL, LDL, and TRIG concentrations, but the significance of these associations is strongly affected by age-specific modifiers. This result is consistent with previous genomewide association data reported in young and adult individuals that showed a complete lack of positional concordance between these 2 groups (Dumitrescu et al., 2011) as well as with the QTL scan for porcine serum lipids traits performed by Gallardo et al. (2008). In humans, there is an increase in the means and variances of blood lipids with age, and longitudinal studies reflect the existence of differential gene expression in adults vs. young people (Dumitrescu et al., 2011). The genetic vs. environmental contributions to this phenomenon are unknown, but sustained environmental exposure to factors such as diet and exercise may play a relevant role (Dumitrescu et al., 2011). 
An illustrative example is provided by the $A B C A 1$ gene, where carriers of inactivating mutations with an age between 30 and $70 \mathrm{yr}$ display much lower levels of HDL than carrier individuals with less than $30 \mathrm{yr}$, while such effect is not observed in unaffected controls (Clee et al., 2000). Age-related gene expression changes can be also produced by epigenetic factors such as differential methylation of certain genomic regions in young vs. old individuals, as demonstrated in human T cells (Heyn et al., 2012) and in the epidermis layer (Raddatz et al., 2013). Therefore, changes in the methylome in piglets vs. adult pigs could be one of the factors explaining the age-specific pattern of associations that we have found for the $A D I P O Q$ genotype.

Finally, we should stress that our study is limited by the fact that we did not analyze the sequence variability of noncoding $A D I P O Q$ regions, such as proximal and distal regulatory elements (promoter, enhancers, etc.) and introns. Given the size of the $A D I P O Q$ gene (around 16 and $13 \mathrm{~kb}$ in humans and cattle, respectively), the identification of the causal mutation associated with lipid phenotypes would necessarily imply the targeted next-generation sequencing of the whole gene and surrounding regions. This strategy should allow generating representative SNP panels that could be used as markers in association and differential allele expression studies.

\section{LITERATURE CITED}

Bischoff, S. R., S. Tsai, N. Hardison, A. A. Motsinger-Reif, B. A. Freking, D. Nonneman, G. Rohrer, and J. A. Piedrahita. 2009. Characterization of conserved and nonconserved imprinted genes in swine. Biol. Reprod. 81:906-920.

Cánovas, A., R. Quintanilla, M. Amills, and R. N. Pena. 2010. Muscle transcriptomic profiles in pigs with divergent phenotypes for fatness traits. BMC Genomics 11:372.

Casellas, J., O. Vidal, R. N. Pena, D. Gallardo, A. Manunza, R. Quintanilla, and M. Amills. 2013. Genetics of serum and muscle lipids in pigs. Anim. Genet. 44:609-619.

Chan, D. C., G. F. Watts, T. W. Ng, Y. Uchida, N. Sakai, S. Yamashita, and P. H. Barrett. 2005. Adiponectin and other adipocytokines as predictors of markers of triglyceride-rich lipoprotein metabolism. Clin. Chem. 51:578-585.

Chandran, M., S. A. Phillips, T. Ciaraldi, and R. R. Henry. 2003. Adiponectin: More than just another fat cell hormone? Diabetes Care 26:2442-2450.

Cieslak, J., T. Flisikowska, A. Schnieke, A. Kind, M. Szydlowski, M. Switonski, and K. Flisikowski. 2013. Polymorphisms in the promoter region of the adiponectin $(A D I P O Q)$ gene are presumably associated with transcription level and carcass traits in pigs. Anim. Genet. 44:340-343.

Clee, S. M., J. J. Kastelein, M. van Dam, M. Marcil, K. Roomp, K. Y. Zwarts, J. A. Collins, R. Roelants, N. Tamasawa, T. Stulc, T. Suda, R. Ceska, B. Boucher, C. Rondeau, C. DeSouich, A. Brooks-Wilson, H. O. Molhuizen, J. Frohlich, J. Genest, and M. R. Hayden. 2000. Age and residual cholesterol efflux affect HDL cholesterol levels and coronary artery disease in ABCA1 heterozygotes. J. Clin. Invest. 106:1263-1270.
Dai, M. H., T. Xia, G. D. Zhang, X. D. Chen, L. Gan, S. Q. Feng, H. Qiu, Y. Peng, and Z. Q. Yang. 2006. Cloning, expression and chromosome localization of porcine adiponectin and adiponectin receptors genes. Domest. Anim. Endocrinol. 30:117-125.

Dall'Olio, S., R. Davoli, L. Buttazzoni, P. Zambonelli, and V. Russo. 2009. Study of porcine adiponectin $(A D I P O Q)$ gene and association of a missense mutation with EBVs for production and carcass traits in Italian Duroc heavy pigs. Livest. Sci. 125:101-104.

Dumitrescu, L., K. Brown-Gentry, R. Goodloe, K. Glenn, W. Yang, N. Kornegay, C. H. Pui, M. V. Relling, and D. C. Crawford. 2011. Evidence for age as a modifier of genetic associations for lipid levels. Ann. Hum. Genet. 75:589-597.

Gallardo, D., R. N. Pena, M. Amills, L. Varona, O. Ramírez, J. Reixach, I. Díaz, J. Tibau, J. Soler, J. M. Prat-Cuffi, J. L. Noguera, and R. Quintanilla. 2008. Mapping of quantitative trait loci for cholesterol, LDL, HDL and triglyceride serum concentrations in pigs. Physiol. Genomics 35:199-209.

Gallardo, D., R. Quintanilla, L. Varona, I. Díaz, O. Ramírez, R. N. Pena, and M. Amills. 2009. Polymorphism of the pig acetyl-coenzyme A carboxylase $\alpha$ gene is associated with fatty acid composition in a Duroc commercial line. Anim. Genet. 40:410-417.

Heyn, H., N. Li, H. J. Ferreira, S. Moran, D. G. Pisano, A. Gomez, J. Diez, J. V. Sanchez-Mut, F. Setien, F. J. Carmona, A. A. Puca, S. Sayols, M. A. Pujana, J. Serra-Musach, I. Iglesias-Platas, F. Formiga, A. F. Fernandez, M. F. Fraga, S. C. Heath, A. Valencia, I. G. Gut, J. Wang, and M. Esteller. 2012. Distinct DNA methylomes of newborns and centenarians. Proc. Natl. Acad. Sci. USA 109:10522-10527.

Hiard, S., C. Charlier, W. Coppieters, M. Georges, and D. Baurain. 2010. Patrocles: A database of polymorphic miRNA-mediated gene regulation in vertebrates. Nucleic Acids Res. 38:D640-D651.

Hivert, M. F., A. K. Manning, J. B. McAteer, J. C. Florez, J. Dupuis, C. S. Fox, C. J. O'Donnell, L. A. Cupples, and J. B. Meigs. 2008. Common variants in the adiponectin gene $(A D I P O Q)$ associated with plasma adiponectin levels, type 2 diabetes, and diabetes-related quantitative traits: The Framingham Offspring Study. Diabetes 57:3353-3359.

Houde, A. A., B. D. Murphy, O. Mathieu, V. Bordignon, and M. F. Palin. 2008. Characterization of swine adiponectin and adiponectin receptor polymorphisms and their association with reproductive traits. Anim. Genet. 39:249-257.

Kadowaki, T., and T. Yamauchi. 2005. Adiponectin and adiponectin receptors. Endocr. Rev. 26:439-451.

Kantartzis, K., K. Rittig, B. Balletshofer, J. Machann, F. Schick, K. Porubska, A. Fritsche, H. U. Häring, and N. Stefan. 2006. The relationships of plasma adiponectin with a favorable lipid profile, decreased inflammation, and less ectopic fat accumulation depend on adiposity. Clin. Chem. 52:1934-1942.

Lara-Castro, C., N. Luo, P. Wallace, R. L. Klein, and W. T. Garvey. 2006. Adiponectin multimeric complexes and the metabolic syndrome trait cluster. Diabetes 55:249-259.

Lawson, H. A., K. M. Zelle, G. L. Fawcett, B. Wang, L. S. Pletscher, T. J. Maxwell, T. H. Ehrich, J. P. Kenney-Hunt, J. B. Wolf, C. F. Semenkovich, and J. M. Cheverud. 2010. Genetic, epigenetic, and gene-by-diet interaction effects underlie variation in serum lipids in a LG/JxSM/J murine model. J. Lipid Res. 51:2976-2984.

Markham, N. R., and M. Zuker. 2008. UNAFold: Software for nucleic acid folding and hybridization. Methods Mol. Biol. 453:3-31.

Melo, C., R. Quintanilla, D. Gallardo, A. Zidi, J. Jordana, I. Díaz, R. N. Pena, and M. Amills. 2013. Association analysis with lipid traits of 2 candidate genes (LRP12 and TRIB1) mapping to a SSC4 QTL for serum triglyceride concentration in pigs. J. Anim. Sci. 91:1531-1537.

Pesole, G., and S. Liuni. 1999. Internet resources for the functional analysis of $5^{\prime}$ and $3^{\prime}$ untranslated regions of eukaryotic mRNA. Trends Genet. 15:378. 
Qiao, L., C. Zou, D. R. van der Westhuyzen, and J. Shao. 2008. Adiponectin reduces plasma triglyceride by increasing VLDL triglyceride catabolism. Diabetes 57:1824-1833.

Raddatz, G., S. Hagemann, D. Aran, J. Söhle, P. P. Kulkarni, L. Kaderali, A. Hellman, M. Winnefeld, and F. Lyko. 2013. Aging is associated with highly defined epigenetic changes in the human epidermis. Epigenetics Chromatin 6:36.

Ronaghi, M., M. Uhlen, and P. Nyren. 1998. A sequencing method based on real-time pyrophosphate. Science 281:363-365.
Rowlan, J. S., Z. Zhang, Q. Wang, Y. Fang, and W. Shi. 2013. New quantitative trait loci for carotid atherosclerosis identified in an intercross derived from apolipoprotein E-deficient mouse strains. Physiol. Genomics 45:332-342.

Wang, J., M. Pitarque, and M. Ingelman-Sundberg. 2006. 3'-UTR polymorphism in the human $C Y P 2 A 6$ gene affects mRNA stability and enzyme expression. Biochem. Biophys. Res. Commun. 340:491-497. 